\title{
Game-Based Language Learning
}

\author{
Paula Escudeiro and Carlos Vaz de Carvalho
}

\begin{abstract}
The European Community is a diverse ensemble of regions, cultures and languages. This is an advantage as it introduces a variance of views and approaches for common problems and issues - however it is also a barrier for companies trying to internationalize or establish joint ventures in the European market or outside of it. The use of an intermediary language, like English or German is an incomplete solution as good commercial relations always depend on full understanding and confidence between the parts. In particular, this can be a problem for Micro Enterprises (start-ups) and SMEs that do not have dedicated staff for this purpose. As a consequence, these companies still depend largely on their domestic markets despite the opportunities made available by the enlarged single market and by globalization at large. Business to Business ( $B$ to B) e-commerce and e-marketing possibilities are not being effectively exploited by these companies. This article presents an approach that seeks to address the reinforcement of Micro and SME's managers' skills in the process of internationalization to internal and external markets through electronic business platforms. Therefore, the project aims for the improvement of languages and culture skills relative to the use of e-marketing and e-commerce tools, the establishment of relations through electronically supported social platforms and the encouragement of entrepreneurship. The project methodology is based on a Serious Game approach that provide rule-based, professional, real-life situations and contexts of interaction where the player tries to achieve learning objectives and improve personal skills and social competencies.
\end{abstract}

Index Terms - Serious games, language learning, game-based learning.

\section{INTRODUCTION}

In the current socio-economic framework, there is a need for businesses to show competitive capacity for development, for instance, by establishing Joint Ventures with other Micro companies and SME's, as there is a direct relation between more international SMEs and more growth and jobs. Internationalised SMEs show better performance, i.e.: are more competitive, than non-internationalised SMEs. Internationalisation supports business sustainability in the long term. This concern is expressed by entrepreneurs and leaders of European businesses:

"A significant percentage of European SMEs does lose business every year as a direct result of linguistic and intercultural weaknesses" [1].

"Longer-term business partnerships depend upon relationship-building and relationship-management. To achieve this, cultural and linguistic knowledge of the target country are essential" [2].

Manuscript received May 17, 2013; revised July 17, 2013.

The authors are with the Instituto Superior de Engenharia do Porto, Portugal (e-mail: pmo@isep.ipp.pt, cmc@isep.ipp.pt).
In this sense, it is very important to develop the intercultural and inter-communication skills of current managers, who intend to internationalize their companies, this way facilitating employability and competitiveness. But at the same time it is necessary to alert and train future entrepreneurs (still in their role of Higher Education students) so that they immediately understand this requirement.

It is consensually accepted that ICT supports the development of innovative learning environments, particularly at the VET system [3]. Thus, the development of innovative ICT-based content available by a mixed of online and mobile platform access and based on a Serious Games approach means an innovative practice for SME development. Serious Games focus on specific design of the learning process, creating real scenarios in professional contexts, in predefined ways through interactive, and immersive graphical environments (2D/3D graphics, sound, and animation) [4]. Every Serious Game has a back-story, or a real-based situation, and a professional context line that it follows, even if inferred. In addition, the interactivity makes possible to know the impact of the player's actions, through answers to questions or situations in virtual scenario.

Serious Games are especially useful for training. Rather than offering traditional paper-based or online static courses, games can offer an incredibly immersive and engaging environment where users 'learn by doing'. Users make and learn from their own mistakes in a controlled environment. This trial and error based approach supports well learning and is able also to improve teamwork, social skills, leadership and collaboration.

For example, Hussain looked at the use of a fantasy based multiplayer game to train teamwork skills in the US army and they found that a training system that used multiplayer games was suitable to elicit teamwork behaviors and to practice this behavior and improve upon it, as well [5].

The most striking effect in the use of Serious Games is an increased motivation and engagement. This was seen in the three main sectors that used currently Serious Games, education, military and medicine. There are a few cases of Serious Games for Management (e.g., the IBM Service Management Virtual Simulator [6], the Houthoff Buruma Game [7], the Novicraft HRD game [8]) but they are still very specific and only for particular contexts.

This article presents an innovative solution for self-based learning, related with identified needs of the target groups at international contexts. The solution will be implemented through an extensible, online, multi-language, multi-player, collaborative and social game platform. The proposal is very innovative because: 1) it addresses a target group (Micro and SME's Managers) for whom training is essentially still class based or static internet delivery based; 2) it introduces a systematic approach to the use of Serious Games for SME's 
Management; 3) combines professional staff with Higher Education students to create an heterogeneous group where practical, professional experience can be combined with academic knowledge; 4) it depicts scenarios very close to the real situations thanks to the collaboration of the end users in the consortium; 5) a mix of online and mobile platform access will allow a personal learning and interactive environment to facilitate the interpersonal and intercultural communication competency development; 6) the platform is expansible, allowing the production and integration of new scenarios.

\section{AIMS AND OBJECTIVES}

The Game-Based Language Learning project has the following generic objectives:

- Reinforcing interpersonal and intercultural competencies relevant to the SMEs internationalization and e-marketing/e-commerce in order to facilitate competitiveness. Micro and SMEs will be able to communicate, establish profitable joint ventures and collaborate.

- Supporting the development of innovative ICT-based content accessed by a mixed of online and mobile platform and based on a Serious Games approach, meaning an innovative practice for SMEs development;

- Bridging, more effectively, the worlds of personal and cultural valorization within work by supporting SMEs managers and Higher Education students throughout individual and flexible learning pathways;

- Promoting cooperation between Universities, VET and world of work, involving representatives from both worlds (e.g. VET and ICT's firms, universities, representative association as well as SMEs and stakeholders) as well as support the dissemination of innovative methods, tools and pedagogical approaches, likely to use in processes of companies' internationalization and finally

- Developing the integration of learning with working life, by promoting more learning conducive environments at the workplace, work-placed training and learning pathways as a basis for development of vocational skills relevant to the labour market needs in times of a globalised world.

GABALL project has the following specific objectives:

- Determining the crucial learning needs for SMEs internationalization by a research phase, the basis for design the more relevant and common professional and cultural situations in that process;

- Designing and producing innovative learning resources (role-playing scenarios) able to support the internationalization between countries, using real situations in professional contexts, meeting the needs of SME's managers and other staff in international business-oriented enterprises;

- Development of a platform \& digital's scenarios, available on online and mobile technologies;

- Ensuring the quality, functionality and suitability of the learning digital scenarios and platform by piloting testing actions involving key end-users in the participating partners' countries and
- To spread out information on the project and its results, in order to guarantee its visibility and developed adequate activities to assure future sustainability your manuscript electronically for review.

The methodology is expected to be reusable in several linguistic and cultural environments and the most concrete developed results will be produced in accordance to the specification for cultural differences. Therefore, the success of the project can lead to quick replication and a strong impact in addressing those challenges. Furthermore, the project's geographical coverage brings the multiculturalism and multi-linguistic aspects into play.

The project combines expertise and experience of various qualified organizations active in the field of Higher Education, business and VET, which allows anticipating a maximum benefit. This covers and assures the active involvement of key actors which will enhance not only a wider dissemination of findings and products but also their usage/adoption in the professional spheres, reaching target groups in countries beyond the consortium.

The proposal contextualizes its innovative dimension in relation to the needs of the target groups which are clearly identified: 1) SMEs managers and VET providers and professionals experts (trainers, consultants); 2) Higher Education students that have the potential to become entrepreneurs. In a lesser degree, other target groups are 3) internationalization stakeholders and business representatives; 4) decision makers and governmental business entities. These groups will be reached mainly through partners' networks and emailing lists and involved in specific activities all along the project.

The project responds to actual needs in terms of promoting competencies for supporting the internationalization of Micro and SMEs. These needs, which have been identified by all partners, are reflected in national policies where counteracting actual situation by means of innovative learning strategies of high quality and tailored to the characteristics and needs of SMEs managers is a vital aspect. On the other side the project can have a strong impact on the way Universities relate to the Society and the Companies, by promoting a more direct relation between those entities.

The products are very relevant to socioeconomic communities, once the project correspond to identify needs, what increases the change to reach those local key actors.

\section{CuRRENT RESEARCH}

The objective of the initial research process was to characterize theoretically the six most relevant and common professional and cultural situations (six scenarios), in processes of SMEs' internationalisation through e-marketing by literature review, personal contacts (at least 5 academic experts and SME's representatives and governmental business entities) and focus group approach. A research plan with the definition of responsibilities among partners and a methodological guideline for the work to be undertaken was developed. In the end a paper was drawn about the six most relevant scenarios for managers into companies that are in internationalization processes.

This resulted from reviewing the literature, contacts with 
key actors and systematization of information, on the most relevant professional and cultural situations (scenarios) in the activities of internationalization, that the business managers face on a daily basis.

Subsequently, each partners' countries developed a "focus group", close to representative of main end users and business stakeholders to confirm/further elaboration of the most relevant scenarios obtained with the previous phase.

Thus meaning assess and analyses the needs and relevant issues of companies' internationalisation by all members of consortium, concerning six professional and cultural situations. At the end, six professional and cultural situations will be feature, directly related to internationalization activities of any company.

Potential language learning scenarios are the following: 1) Internationalization 2) Markets and Innovation 3) Financing and tax Obligations 4) E-commerce terms 5) E-Marketing terms 6) Legal and institutional environment and 7) Cultures.

In the end, all the work and findings were compiled into a report, covering the characterization of the six scenarios. This report also addresses the delivery form for the language learning scenarios, that is, how to integrate it with the professional life of the SME's staff and the academic activities of the students.

Then the professional situations in interactive scenario scripts, based on the previous scenarios characterisation will be developed. The dialogues were elaborated from work contexts (professional situations) to dialogues in the context of self-learning (pedagogical situations). Each situation of self-learning should contain also a self-assessment dimension. They are implemented through collaborative work with the teams formed for each specific task (involving brainstorming, activities of exploration / discussion group, et al.).

This way the six scenarios in English will be set for a self-based learning (role-playing scenarios + self-assessment). Nevertheless, these scenarios can also be integrated in the curricula of academic disciplines for the Higher Education students. Next, the scenarios will be translated. In the end, Virtual Campus will assemble all the materials into a unique document, a crucial input for the next WP.

The major skills areas required to do business abroad would be commercial, e-intelligence, and market research. Commercial area, besides covering international networking, includes all the aspects related with culture and language. The way of doing business is different from country to country (in some cases the cultural gap is huge); moreover, knowledge about legal issues and institutions is also very important, and therefore identifying local partners is fundamental in internationalization context.

The target groups outline 3 major skills areas required to successfully do and open business abroad:

- legal and institutional environment;

- markets and innovations;

- tax and finances.

The priority was also given to the international networking, language and culture, .e-commerce and e-marketing. The most relevant competences for internationalisation are:

- International networking

- Tax and finance
- Legal and institutional environment

- Cultures

The target groups outline 4 major skills areas required to successfully do and open business abroad:

- markets and innovations;

- international networking;

- intercultural differences;

- Legan and institutional environment.

Tax and finances and e---commerce and e---marketing had a small importance at this process, because of the type of business of the most part of companies (services (e. g web development, not physic products).

Specific situations (scenarios) identified for the above areas are mainly associated with cultural aspects when negotiating with firms from different countries/regions and with international networking when participating in international trade fairs. Depending on the countries/regions, the scenarios can vary completely (ex: logistics in Africa transport in Eastern Europe, cultural aspects in Asia).

It was difficult for the respondents to verbalize the scenarios related to the skills areas. Nevertheless some may be stated as very important: types and dimension of taxes and social contributions, legislation in relation to company registration, judicial system.

- International networking Clusters

- Virtual parks

- On-line collaboration

- Planning a participation in a fair

- Attend the event (number of people, what to show)

- Manage an international network

- Negotiate

- Agreements

- Communication

- The first attempt to internationalization of Brazilian companies through business partners

- It is important to understand approach techniques

- Social networking through exhibitions, events and other activities

- CultureGreetings

- Timing (meals, rest, leisure)

- Visit other companies

- Cultural approach of the negotiation

- Business culture

- Culture of relations at and out of the working place

- Relations in an international company

- Religious holidays and customs

- Necessary to an external market operator a prominent general culture (knowledge)

- Products and services are subject to adjustments upon the culture of the country

- Different time zone directly influences the relationship with managers

- Local holidays, related to one a specific town or state

- Tax and finance Information about the tax

- Ask for a financial grant

- Know fees and internal regulations about a product or service

- Check whether there are trade barriers

- Understand the logistic processes

- Legal and institutional environment Institutional 
negotiation

- Develop a legal agreement

- Documentation management

- Institutions (where to go)

- On the sale of physical products, it is important to know the legal aspects of the process of export-import

- Languages Greetings - business

- Contract negotiation

- Managing business situation

- Relations with administration

- Markets and innovation Know competitors in the external market as well as

- products / similar services

- Logic operations of a market

- Variables in the buyer / distributor and consumer

- Market

- Know the values practiced by foreign markets, as well as the quality of services and professionals level.

- Necessary understand the quality of service/product expected for each country

- Manager needs to know e-marketing tools

In relation to the need for foreign language training in the above skill areas, respondents vary in their opinion. Nonetheless, the situation seems to be difficult for the majority of Portuguese SMEs that might select Brazil and Angola as preferred markets for doing business, only because these entrepreneurs do not speak English. All agree that internal human resources assigned to work with international markets need to have a good level of English.

The targeted respondents expressed their need for studying foreign languages. Preferences fall to English. It was also mentioned, that the language chosen depends on the country of the internationalization. Majority of the respondents would prefer intermediate and advanced levels to be achieved.

The main language used by Spanish companies in international markets is English. Even of the staff over 55 knows better French language (before 70's the foreign language learnt during the educational process in Spain was French).

In the last year new language has been incorporated to the portfolio of the companies as German and a basic knowledge of Chinese. But English is the language more used for international relations.

The target groups expressed their need for studying foreign languages. Half of them need to study English and a third - German, the same percentage ratio is true for the language level to be achieved, respectively advanced and intermediate.

Approximately $85 \%$ of respondents recognized the need to incorporate trainings related to learning new languages, especially English, into companies. This is due to the fact that the Brazilian professionals have little knowledge in other languages, thus, the solution presented by the companies is internal training, lessons for the companies.

\section{CONCLUSION}

The choice of a Serious Game approach will ensure achieving a remarkable impact, because Serious Games facilitate motivation and engagement. Without motivation there is no learning and the engagement that games produce is hard to match with any other training methods.

If the game structure is directly related to the learning objectives, as in a simulation, it can be even more effective, since it combines the challenge of a game with a safe place to practice real-life skills, and most importantly to make mistakes and to fail. The contextual nature of digital game-based learning highlights its effectiveness partly because the learning takes place within a meaningful (to the game) context. What should be learnt is directly related to the environment in which you learn and demonstrate it; thus, the learning is not only relevant but applied and practiced within that context.

The target groups will be reached after the project is finished in different ways:

- The educational/training partners will integrate and use the platform in their daily academic/VET work addressing Higher Education students and SMEs managers;

- The European managers and others staff in EU countries who are involved in internationalisation activities. For this target group it is expected that they might be interested in learning through role-playing scenarios, available over online or mobile platforms, concerning real situations and professional issues;

- VET professionals that will have available a new tool for improving the personal and professional competencies/qualifications for different target audiences, and in this way introduce the use of Serious Games for improving the skills of SMEs managers;

- Universities and higher institutes which can improve the methodologies of teaching and learning through Serious Games approach. This approach allows designers to associate games and simulations to their learning designs, the basis for an innovative pedagogical methodology;

- ICT's firms that can explore the potentialities of Serious Games approach in order to expand and improve the themes and technologies used in this kind of pedagogical and informational documents, specially the game designers who are being asked to include instructional elements within game play and are looking for guidance on how to make those additions, and finally.

- Representative associations which can develop a strait connection with their representatives in order to promoting the personal qualifications and the competitive capacity of European enterprises, but, above all, enabling business decision-makers to continue exploring ways to reach an increasingly wired, hyper-connected workforce already accustomed to anytime, anywhere access to ideas, information, and contacts.

\section{ACKNOWLEDGEMENTS}

This work has been partly supported by the European Commission through its European Agency for Culture, Education, Audiovisual in the scope of the Lifelong Learning Programme, KA2 sub-programme, GABALL project (ref. 531327-LLP-1-2012-1-PT-KA2-KA2MP).

\section{REFERENCES}

[1] EU Commission, Internationalisation of European SMEs - Final report, pp. 16, 2010. 
[2] EU Commission, Languages mean business - Companies work better with languages: Recommendations, 2008.

[3] R. Batista and C. V. Carvalho, "Learning through role play games," in Proc. FIE 2008 - 38th IEEE Annual Frontiers in Education Conference, October 2008.

[4] C. V. Carvalho, "Games for e-learning," IJITCS - International Journal of Information Technology and Computer Science, pp. 61-67, vol. 4, issue Jul/Aug 2012, ISSN 2091 - 1610.

[5] T. S. Hussain and W. Ferguson, "Efficient development of large-scale military training environment using a multi-player game," in Proc. the 2005 Fall Simulation Interoperability Workshop, paper 05F-SIW-060, Orlando, FL, 18-23 September, 2005, pp. 421-431.

[6] IBM. Service management Simulator. [Online]. Available: http://www-01.ibm.com/software/tivoli/features/sm-simulator/

[7] R. Buruma and H. Buruma. Houthoff Buruma - The Game. [Online] Available: http://www.ranj.com/content/werk/houthoff-buruma-the-game

[8] Novicraft. Novicraft Game. [Online]. Available: http://www.novicraft.com/

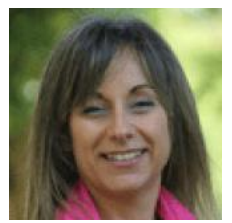

Paula Escudeiro has a $\mathrm{PhD}$ in informatics/information systems from the Open University in Portugal. She is a Professor at IPP-ISEP with vast experience in project supervision and evaluation, accumulated for the past 21 years. She has prior experience on software industry related to the development of educational software. She is the director of the Multimedia Laboratory at ISEP and belongs to the Graphics, Interaction and Learning Technologies research center (GILT)

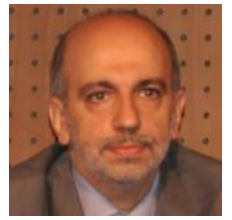

Carlos Vaz de Carvalho holds a PhD in information systems and technology from the School of Engineering, University of Minho. He is a Professor in the Department of Computer Engineering from the Engineering Institute (ISEP) of the Polytechnic of Porto. He was a researcher at INESC (Group for Computer Graphics), an institution of private R \& D between 1988 and 1996. Thereafter, he developed his scientific career in the field of e-learning at ISEP, where he is currently the Director of GILT (Graphics, Interaction \& Learning Technologies) an R\&D Group. He has tutored/is tutoring eight doctoral thesis and $30 \mathrm{MSc}$ dissertations, authored over 125 publications and communications, including nine books (as author and editor) and participated in over 20 national and European projects, coordinating seven of them. 